02

\title{
Исследование пропускания легированного железом селенида цинка в терагерцовом диапазоне частот*
}

\author{
(C) М.О. Жукова ${ }^{1}$, Я.В. Грачев ${ }^{1}$, А.Н. Цыпкин ${ }^{1}$, С.Э. Путилин ${ }^{1}$, \\ В.П. Чегнов ${ }^{2}$, О.И. Чегнова ${ }^{2}$, В.Г. Беспалов ${ }^{1}$ \\ ${ }^{1}$ Университет ИТМО, \\ 197101 Санкт-Петербург, Россия \\ ${ }^{2}$ НИИ Материаловедения, \\ 124460 Москва, Россия \\ e-mail: mozhukova@corp.ifmo.ru
}

Поступила в редакцию 24.12.2017 г.

Представлены результаты экспериментального исследования пропускания пластин кристалла селенида цинка, легированного железом на уровне 0.23 масс.\%, в терагерцовом диапазоне частот и сравнение с пропусканием нелегированных образцов. Показано, что наличие примесей железа в образце селенида цинка делает среду более прозрачной в диапазоне частот от 0.35 до $0.5 \mathrm{THz}$. Пропускание легированного образца в этом диапазоне возрастает до $20 \%$ по сравнению с чистым $\mathrm{ZnSe}$, что может быть использовано в дальнейшем для создания эффективных устройств управления терагерцовым излучением.

DOI: $10.21883 /$ OS.2018.05.45947.308-17

\section{Введение}

Терагерцовый диапазон частот в последние десятилетия привлекает все больше внимания, что связано с перспективными возможностями использования в системах неинвазивного контроля [1-3], безопасности [4], сверхбыстрой передачи информации [5]. Перспективы и возможности использования терагерцовых систем ограничены в первую очередь нехваткой материалов для создания генераторов, детекторов и преобразователей терагерцового (ТГц) излучения. В настоящее время возрос интерес к созданию различных метаматериалов, композитов $[6,7]$ к использованию органических кристаллов [8] в качестве компонентов ТГц систем. Но интерес к более привычным материалам ТГц диапазона, таким как полупроводниковые кристаллы, до сих пор не исчерпан, особенно с появлением возможности использовать более мощные источники сверхкоротких импульсов накачки.

В предыдущих работах авторов $[9,10]$ рассматривалась возможность поиска оптимальных значений интенсивности используемого лазерного излучения для электрооптического преобразования в кристаллах $\mathrm{ZnTe}, \mathrm{ZnSe}$ и GaP. C одной стороны, использование более мощных источников накачки может увеличить эффективность преобразования и создания высокоинтенсивных источников ТГц излучения для большей глубины проникновения в образцы при спектроскопических исследованиях [11], a также для большей дальности передачи сигналов в системах беспроводной коммуникации [12]. Но было показано, что увеличение интенсивности оптического излучения приводит к ряду негативно влияющих на эффективность электрооптических преобразований нели-

* Х Международная конференция молодых ученых и специалистов „Оптика 2017“, 16-20 октября 2017 г., Санкт-Петербург, Россия нейных процессов, таких как двухфотонное поглощение [13]. Варьируя интенсивность излучения накачки в экспериментах по спектроскопии накачка-зондирование, удалось получить данные о дисперсии нелинейного показателя преломления $n_{2}$ и определить оптимальный уровень оптического излучения для предотвращения возникновения нежелательного нелинейного отклика и обеспечения эффективной работы систем.

На эффективность электрооптического преобразования из оптического в ТГц диапазон частот также влияет количество электронно-дырочных пар [14], которое можно увеличивать, например, путем введения примесей в полупроводниковые кристаллы. В настоящей работе рассматривается изменение пропускания кристаллической пластины селенида цинка $(\mathrm{ZnSe})$ до легирования и после легирования ионами железа $(\mathrm{Fe})$ с концентрацией на уровне 0.23 масс. $\%$.

\section{Методы исследования}

Образцы для исследований были приготовлены диффузией железа в нелегированные кристаллы ZnSe. Нелегированные кристаллы были получены в кварцевых ампулах методом свободного роста из газовой фазы в атмосфере гелия на (111) монокристаллические затравки ZnSe (метод Маркова-Давыдова [15]). Исходной загрузкой служил синтезированный из паровой фазы поликристаллический $\mathrm{ZnSe}$, чистота которого, согласно данным ICP-MS, составляла 99.999 масс.\% [16]. Легированные железом образцы селенида цинка толщиной $1 \mathrm{~mm}$ получали методом диффузии в запаянных ампулах при температуре $1000^{\circ} \mathrm{C}$. Длительность диффузионного процесса составляла 200 h. Концентрация Fe в исследуемых образцах, определенная рентгенофлуоресцентным 


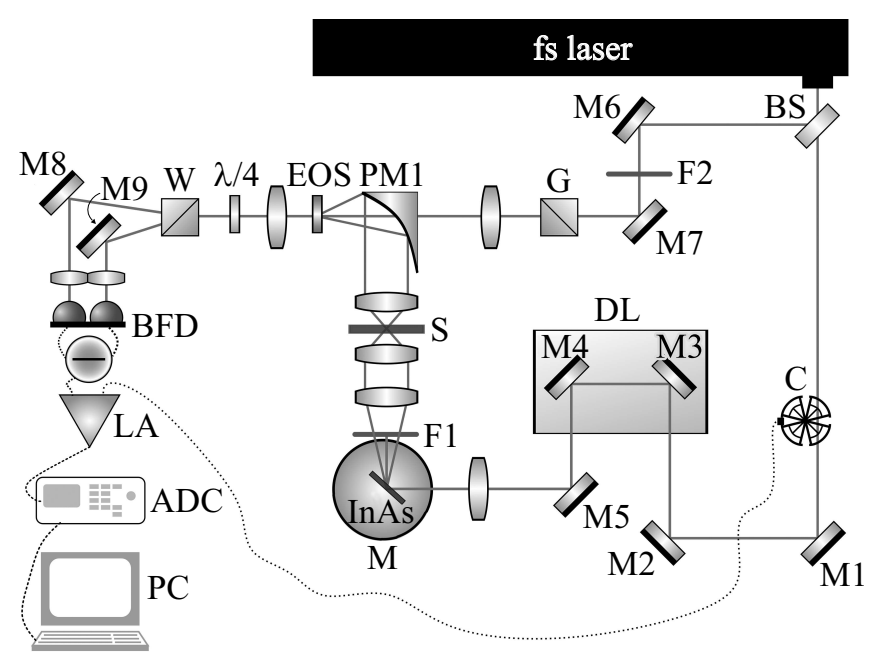

Рис. 1. Схема экспериментальной установки терагерцового спектрометра с разрешением во времени: BS - светоделитель, M1-M9 - зеркала, C - модулятор, DL - линия задержки, M - магнит, F1-F2 - фильтры, S - образец, PM1 параболическое зеркало, G - призма Глана, W - призма Волластона, BFD - балансный фотодетектор, LA - синхронный усилитель, АDC - аналого-цифровой преобразователь, РС компьютер.

методом на спектрометре М-1 Мистраль (Bruker), составила 0.23 масс.\%.

Исследование пропускания образцов проводилось на установке терагерцовой спектроскопии с разрешением во времени (схема установки рис. 1). Источником оптического излучения служил иттербиевый твердотельный фемтосекундный лазер на длине волны $1050 \mathrm{~nm}$ с длительностью импульса $<100 \mathrm{fs}$, частотой повторения $70 \mathrm{MHz}$ и выходной энергией в импульсе $>50 \mathrm{~nJ}$. $\mathrm{B}$ качестве источника терагерцового излучения использовался кристалл арсенида индия (InAs), помещенный в магнитное поле с индукцией $2.4 \mathrm{~T}$ [17]. Излучение фемтосекундного лазера разделялось светоделителем BS на пробный пучок и пучок накачки. Пучок накачки модулировался с помощью оптического механического модулятора $\mathrm{C}$, проходил через линию задержки и фокусировался на кристалл-генератор М. ТГц излучение генерируется за счет фотоэффекта Дембера [18] и сдвига подвижных электронов магнитным полем [17]. Тефлоновый фильтр F1 блокировал излучение накачки. Терагерцовое излучение с помощью системы линз фокусировалось на объекте S. Прошедшее ТГц излучение затем фокусировалось на электрооптическом кристалле ЕОС с помощью параболического зеркала PM1. Фильтр F2 использовался для уменьшения интенсивности пробного пучка. Проходя через призму Глана, поляризация излучения пробного пучка поворачивалась до $45^{\circ}$ по отношению к поляризации ТГц излучения. Пробный пучок пересекался с ТГц в электрооптическом кристалле [100] CdTe, где его поляризация изменялась на величину ТГц поля из-за эффекта Поккельса. Точка пересечения ТГц и фемтосекундных импульсов во временной области регулировалась с помощью оптической линии задержки (DL), что позволило прописать временную форму сигнала. Наведенное изменение поляризации было измерено на системе, состоящей из четвертьволновой пластинки $(\lambda / 4)$, призмы Волластона $(\mathrm{W})$ и балансного фотодетектора (BFD) [19]. Синхронный усилитель LA использовался для повышения отношения сигнал/шум. Усиленный сигнал передавался на компьютер (РС) через аналого-цифровой преобразователь (ADC). Контроль работы установки и записи данных был реализован в программной среде LabVIEW (National Instruments).

\section{Результаты экспериментов}

В работе рассматривается пропускание двух образцов кристаллического селенида цинка $\mathrm{ZnSe}$ ориентации (111) нелегированного и с примесями железа
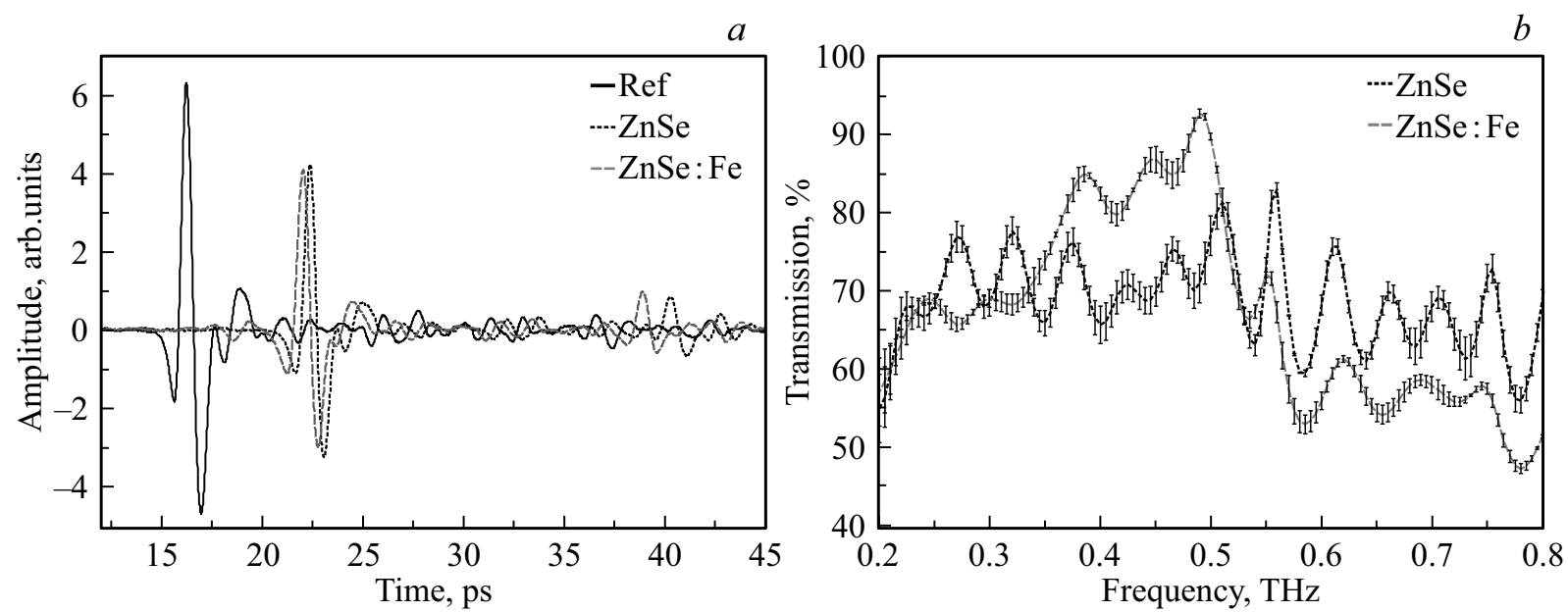

Pис. 2. (a) Терагерцовые импульсы опорного и объектных сигналов во временной области; $(b)$ спектры пропускания ZnSe и $\mathrm{ZnSe}: \mathrm{Fe} \mathrm{Fe}=[0.23$ масс.\%] в ТГц диапазоне частот. 
$\mathrm{ZnSe}: \mathrm{Fe}$ с концентрацией на уровне 0.23 масс.\%, представляющих собой пластинки толщиной $0.61 \mathrm{~mm}$.

В результате проведения серии экспериментов были зарегистрированы временные формы терагерцового электрического поля опорного (без образца) импульса и прошедших сквозь оба образца объектных импульсов. Усредненные значения представлены на рис. 2, $a$ соответственно для опорного импульса - Ref (здесь и далее обозначения на графике), для импульса, прошедшего сквозь пластинку селенида цинка - $\mathrm{ZnSe}$, и через пластину легированного железом селенида цинка $\mathrm{ZnSe}: \mathrm{Fe}$.

Затем из полученных временных зависимостей электрического поля $E(t)$ терагерцового импульса с помощью преобразования Фурье были вычислены комплексные спектры опорного сигнала $G_{\text {ref }}(\omega)$, и двух объектных $G_{\mathrm{ZnSe}}(\omega)$ и $G_{\mathrm{ZnSe:Fe}}(\omega)$. Для расчета спектра пропускания двух образцов использовались следующие соотношения:

$$
\begin{gathered}
T_{\mathrm{ZnSe}}(\omega)=\frac{\left|G_{\mathrm{ZnSe}}(\omega)\right|}{\left|G_{\mathrm{ref}}(\omega)\right|} ; \\
T_{\mathrm{ZnSe}: \mathrm{Fe}}(\omega)=\frac{\left|G_{\mathrm{ZnSe}: \mathrm{Fe}}(\omega)\right|}{\left|G_{\mathrm{ref}}(\omega)\right|},
\end{gathered}
$$

Полученные в результате преобразования спектры пропускания двух образцов приведены на рис. 2, $b$. Из графика пропускания видно, что в частотном диапазоне $0.35-0.5 \mathrm{THz}$ пропускание $\mathrm{ZnSe}: \mathrm{Fe}$ увеличивается, что отличается от общепринятых представлений об увеличении поглощения более плотными средами. Подобные явления ранее наблюдались и в других кристаллах [20-21].

\section{Выводы}

В работе исследовано пропускание кристаллических пластин нелегированного селенида цинка и с примесями железа на уровне 0.23 масс.\% методом терагерцовой спектроскопии с разрешением во времени. Экспериментально показано, что наличие примесей железа в образце селенида цинка делает среду более прозрачной в диапазоне частот от 0.35 до $0.5 \mathrm{THz}$. Пропускание легированного образца в этом диапазоне возрастает до $20 \%$ по сравнению с чистым $\mathrm{ZnSe}$.

Важно заметить, что основное влияние на генерацию/детектирование ТГц импульса в кристаллах оказывает электрооптический эффект. При легировании $\mathrm{ZnSe}$ ионами Fe до определенной концентрации поляризуемость молекулы увеличивается, что увеличивает электрооптический коэффициент и нелинейность $\chi^{(2)}[22,23]$. Это интересное свойство может быть использовано в дальнейшем для создания более эффективных генераторов и детекторов терагерцового излучения, а также устройств для управления ТГц импульсами. При слишком большом проценте легирования нарушается упорядоченность решетки кристалла, что негативно сказывается на эффектах преобразования.
Работа выполнена при государственной финансовой поддержке ведущих университетов Российской Федерации (субсидия 074-U01) и Правительством Российской Федерации (проект 3.9041.2017/7.8).

\section{Список литературы}

[1] Massaouti M., Daskalaki C., Gorodetsky A., Koulouklidis A.D., Tzortzakis S. // Appl. Spectroscopy. 2013. V. 67. N 11. P. 1264.

[2] Balbekin N.S., Novoselov E.V., Pavlov P.V., Bespalov V.G., Petrov N.V. // SPIE Proc. 2014. V. 9448. P. 94482D.

[3] Черкасова О.П., Назаров М.М., Ангелуи А.А., Шкуринов А.П. // Опт. и спектр. 2016. Т. 120. № 1. С. 59.

[4] Ergün S., Sönmez S. // J. Military and Information Science. 2015. V. 3. N 1. P. 13.

[5] Liu C., Wang C., Cao J.C. // J. Optical Technology. 2017. V. 84. N 1. P. 74.

[6] Ma F. Lin Y.S., Zhang X., Lee C. // Light: Science \& Applications. 2014. V. 3. N 5. P. e171.

[7] Золотовский И.О., Коробко Д.А., Минвалиев Р.Н., Остаточников В A. // Опт. и спектр. 2014. Т. 117. № 5. С. 847.

[8] Hauri C.P., Ruchert C., Vicario C., Ardana F. // Appl. Phys. Lett. 2011. V. 99. N 16. P. 161116.

[9] Osipova M.O., Makarov E.A., Bespalov V.G. // Laser Optics (LO), 2016 International Conference // IEEE. 2016. P. R8-45.

[10] Zhukova M., Makarov E.M., Putilin S., Tsypkin A., Chegnov V., Chegnova O., Bespalov V. // J. Physics: Conference Series. 2017. V. 917. N 6. P. 062021.

[11] Mishra P.K., Vendrell O., Santra R. //Angewandte Chemie International Edition. 2013. V. 52. N 51. P. 13685.

[12] Shams H., Seeds A. // Optics and Photonics News. 2017. V. 28. N 3. P. 24.

[13] Gaivoronsky V.Y., Nazarov M.M., Sapozhnikov D.A., Shepelyavyi Y.V., Shkel'nyuk S.A., Shkurinov A.P., Shuvaev A.V. // Quant. Electron. 2005. V. 35. N 5. P. 407.

[14] Ascázubi R., Shneider C., Wilke I., Pino R., Dutta P.S. // Physical Review B. 2005. V. 72. N 4. P. 045328.

[15] Марков Е.В., Давыдов А.А. // Изв. АН СССР. Неорганические материалы. 1975. Т. 11. № 10. С. 1755.

[16] Avetissov I., Mozhevitina E., Khomyakov A., Avetisov R., Davydov A., Chegnov V., Chegnova O., Zhavoronkov N. // CrystEngComm. 2015. V. 17. P. 561.

[17] Bespalov V.G., Krylov V.N., Putilin S.E., Stasel'ko D.I. // Opt. Spectrosc. 2002. V. 93. N 1. P. 148.

[18] Klat G., Hilser F., Qiao W., Beck M., Gebs R., Bartels A., Fischer M. // Opt. Express. 2010. V. 18. N 5. P. 4939.

[19] $W u$ Q., Zhang X.C. // Appl. Phys. Lett. 1995. V. 67. P. 3523.

[20] Red'kin R.A., Bereznaya S.A., Korotchenko Z.V., Sarkisov S.Y. // Proc. of Control and Commun (SIBCON). 2005. P. 1.

[21] Wang Y., Ni H., Zhan W., Yuan J., Wang R. // Optical Materials. 2013. V. 35. N 3. P. 596.

[22] Kong Y., Liu S., Xu J. // Materials. 2012. V. 5. N 10. P. 1954.

[23] Shen X., Yan W., Shi L., Wang Y., Jia F., Qiao H., Lin A. // IEEE Photonics J. 2012. V. 4. N 5. P. 1892. 